\title{
Swyer James Macleods Syndrome of the Right Lung in an Adult Female
}

\author{
Parvaiz A. Koul, Umar Hafiz Khan, Rafi Ahmad Jan, Sanaullah Shah, Abdul Ahad Wani, Sheikh Hilal, \\ M. Ashraf, Feroz Ahmad \\ Department of Internal and Pulmonary Medicine, Sher-i-Kashmir Institute of Medical Sciences, Srinagar.
}

\section{ABSTRACT}

Twenty-four year young female presented with a 6-year history of recurrent chest infections with exertional dyspnea. Radiographic imaging revealed hyertransluscency of the right lung with reduced lung volume and reduced prominence of the right pulmonary vasculature. CT of the chest revealed air trapping and hypertranslucency of the right lung with reduced volume and a less prominent right pulmonary artery and its branches. CT angiography confirmed a hypoplastic right pulmonary artery and its branching, features consistent with Sweyer James Macleod's syndrome. CT angiography could be the preferred modality for non invasive diagnosis of Macleod's syndrome. (JMed Sci 2009;12(1):14-17)

Key words: Macleod's syndrome, Bronchiectasis, Lung, CT, Angiography.

\section{Introduction}

In 1952, Swyer and James published a report on a 6year-old child with unilateral pulmonary emphysema that was treated with pneumonectomy. ${ }^{1}$ The patient had a clinical history of recurrent broncho-pneumonia and bronchitis that affected only the right lung. Chest radiographs revealed relative hyperlucency of the right lung field with a significant decrease in vascular markings. The resected lung had multiple cystic spaces, emphysema, chronic inflammatory changes, and unremarkable bronchi. The authors suggested that the condition was probably acquired as a result of recurrent episodes of bronchopneumonia and bronchitis. One year later,

Reprint Request:

Dr. Parvaiz A Koul

Professor \& Head

Internal \& Pulmonary Medicine

Sher-i-Kashmir Institute of Medical Sciences

Srinagar 190011, J\&K (India)
Macleod described 9 patients with the same syndrome with similar hyperlucency in left lung. ${ }^{2}$ It is now believed to be a post-infective form of bronchiolitis obliterans (BO) most often following a viral infection ${ }^{3,4}$ but also described after tuberculous and mycoplasma pneumonia. ${ }^{2,5,6}$ Most patients are diagnosed in childhood when they present with recurrent respiratory tract infections. A few patients, however, remain asymptomatic until adulthood, when diagnosis is made either incidentally or with symptoms. We herewith describe a patient with Macleod's syndrome who had remained asymptomatic well into her adult life.

\section{Case Report}

A 24 year old female presented with a 6-year history of recurrent chest infections and dyspnea on exertion. There was no accompanying fever, weight loss, night sweating, hemoptysis or a contact history of tuberculosis. Physical examination revealed an average built young female without any dyspnea at rest. The pulse was $84 / \mathrm{min}$, the blood pressure $120 / 70 \mathrm{~mm} \mathrm{Hg}$ and the respirations 18 
per minute with a normal body temperature. Clinical examination of the chest revealed flattening, normally resonant percussion note, reduced air entry and scattered crackles on the right thorax. Rest of the general physical and systemic examination was normal. The hemoglobin concentration was $12.5 \mathrm{~g} / \mathrm{dl}$, the leukocyte count $8.3 \times 10^{9} / 1$ with a normal differential and a normal platelet count. Routine serum biochemistry was normal. The electrocardiogram was normal. Radiograph of the chest showed a hyperlucent right lung with reduced lung volume, mediastinal shift to the right, elevated right hemidiaphragm and less prominent pulmonary vasculature on the right side (Fig. 1). A flexible bronchoscopy was normal. Pulmonary function tests revealed mild restriction. CT images obtained in

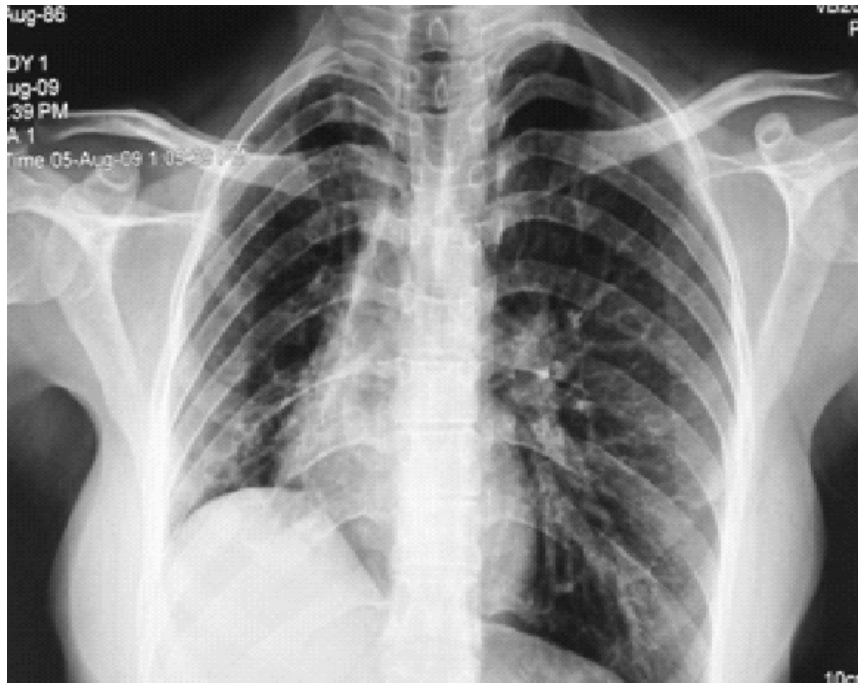

Figure 1: CX ray showing shift of trachea and hyperlucency with decreased vascular markings on right side

expiration showed air trapping in the hyperlucent right lung, right upper and lower lobe. There was herniation of the left lung with shift of mediastinum towards right (Fig. 2). The right lower lobe and right middle lobe revealed evidence of severe bronchiectasis. The left pulmonary arterial system was patent and of normal size but the pulmonary artery and its branches were smaller and pruned on the right. Pulmonary 3D MDCT angiography showed a hypoplastic right pulmonary artery with reduced branching of branches and a pruned peripheral vasculature (Fig. 3). A diagnosis of SJS, associated with bronchiectasis, was made. The patient was managed conservatively and is under followup.

\section{Discussion}

SJMS is a rare syndrome and was reported in $0.01 \%$ of 17,450 survey chest radiograph ${ }^{7}$. It constitutes one of the of several causes of unilateral translucent lung. ${ }^{8-10}$ More than 100 cases have been described in literature. It is a post infectious form of bronchiolitis obliterans (BO)

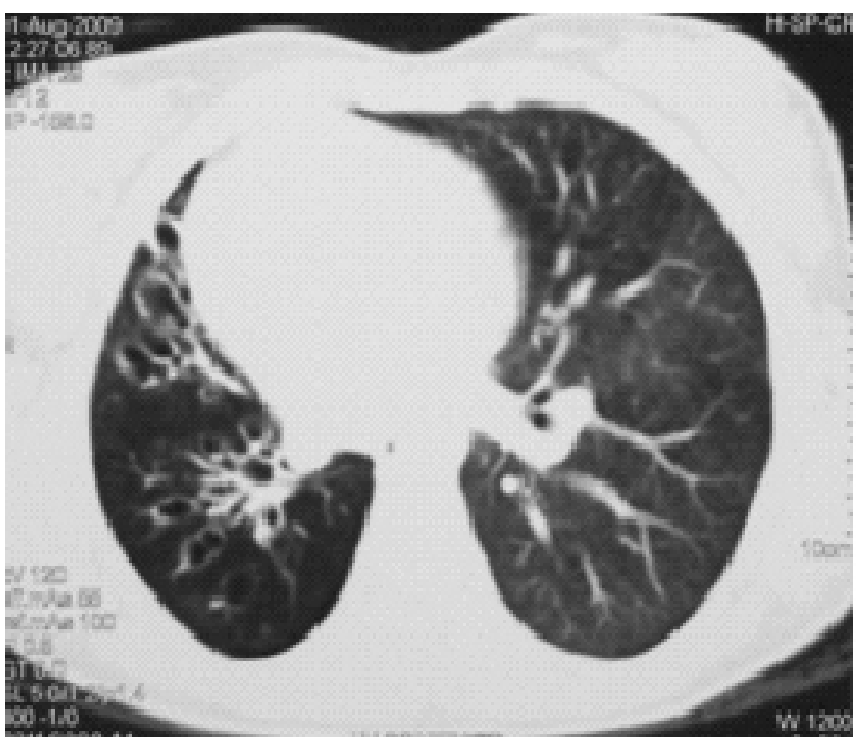

Figure 2: HRCT demonstrating herniation of left lung towards right with bronchiectasis.

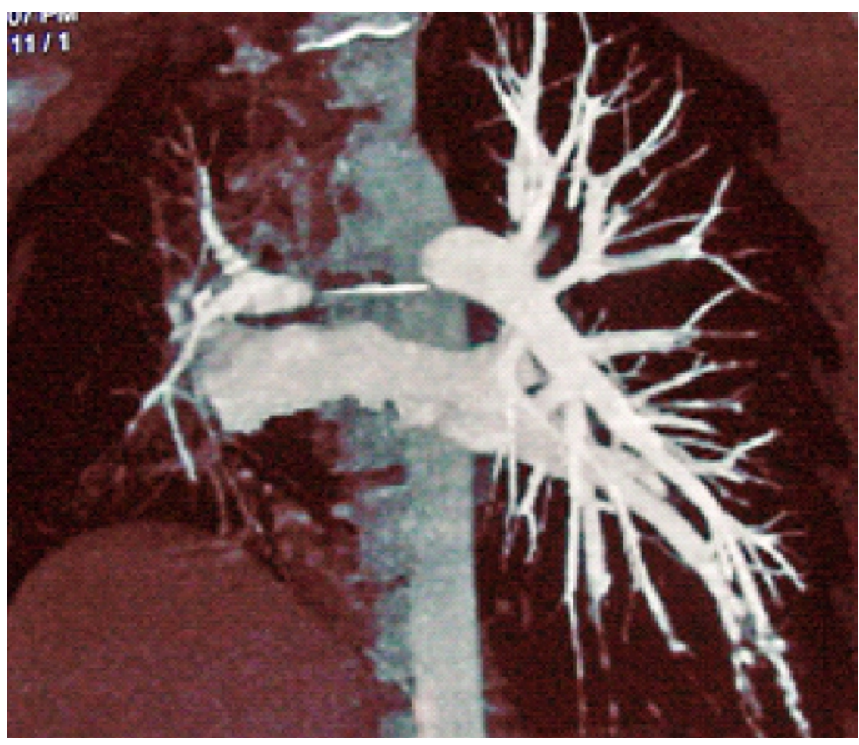

Figure 3: CT angiography showing a small right pulmonaryartery and decreased vascularity.

characterized by the presence of submucosal and peribronchiolar fibrosis with destruction and obliterative scarring of the small airways., ${ }^{3,4}$ While bronchiolitis obliterans accounts for the major part of the underlying pathogenesis, reflex pulmonary vasocons-triction and hypoperfusion resulting in hypoplasia of pulmonary vasculature also contributes to hyperlucency of the pathologic lung. ${ }^{11}$ In addition, fibrosis of the interalveolar septae causes obliteration of the pulmonary capillary bed and secondarily diminishes blood flow to the major pulmonary artery segments, resulting in the hypoplastic arterial development as observed in SJMS. A reduction in ventilation additionally causes a compensatory decrease in perfusion. Hyperexpansion of the terminal air sacs 
secondary to bronchiolar obstruction of the peripheral airways offers additional mechanical resistance to flow through the alveolar capillaries and contributes to atrophy of the vascular beds. ${ }^{12}$ This may be a probable physiological protective mechanism to lessen effect of ventilation and perfusion mismatch in the case of lung damage. Some infection including pertussis, adenovirus, measles, mycoplasma have been described in previous reports to be associated with SJMS. ${ }^{5,613-16}$ As SJMS is an unusual complication of bronchiolitis, it is likely that other common respiratory viral infection of bronchiolitis such as respiratory syncytial virus may also result in SJMS.

SJMS presents with variable clinical features. Patient can be completely asymptomatic with a hyperlucent lung field being an incidental finding. Alternatively, they may have chronic cough, haemoptysis, exertional dyspnoea, recurrent chest infection or other respiratory symptoms secondary to bronchiectasis. ${ }^{7,11,16}$ Our patient presented with history of recurrent chest infections and exertional dyspnea. Although classically involving an entire lung, the disorder can be lobar or segmental. In contrast to our patient left lung has been reported to be involved more commonly in SMJS. In the case series of 13 patients reported by Lucaya $e t a l^{16}$, only 2 patients had unilateral involvement of the right lung whereas in another study right lung involvement was reported in 2 of 9 cases. ${ }^{17}$ The predilection of the left lung to obstruction and subsequent recurrent infections may be related to anatomical and hemodynamic factors. ${ }^{16}$ These include greater length, narrower diameter, and more horizontal angulation of the left main bronchus. It may be related to its course in the sub-aortic tunnel and hilum. ${ }^{16}$

Radiological differential diagnosis for this disorder is varied. The radiological abnormality may be the consequence of congenital pulmonary artery agenesis/hypoplasia or acquired stenosis or compression of main pulmonary vessels. On the other hand, parenchymal disease including congenital lobar emphysema, bronchogenic cyst, bronchiectasis with air trapping, emphysematous bulla, emphysema resulting from bronchial stenosis and bronchospasm may give rise to similar radiological appearance. ${ }^{7}$

The diagnosis of SJS is usually made on the basis of radiographic findings of hyperlucency of a lung or lobe, which results from air trapping during expiration and decreased pulmonary vascular markings in the involved area. ${ }^{16,18-20}$

High resolution computerized tomography scan of the chest is essential not only in excluding other causes of unilateral hypertranslucency but also in determining the presence and type of bronchiectasis. Computerized tomography helps to exclude central bronchial obstruction (making bronchoscopy unnecessary in some cases), cysts and vascular diseases as causes of hyperlucency.
Bronchiectasis is not a universal finding in SJMS. There are several explanations for bronchiectasis.1) bronchiolitis obliterans (BO) causing atelectasis or scarring which in turn leads to bronchial dilatation, ${ }^{23}$ 2) bronchiectasis itself being the primary event with distal spread to peripheral small airways leading to obliteration, 3) the initiating viral infection might damage both bronchioles and bronchi simultaneously. Both cylindrical and saccular brochiectasis can be found in SMJS. Patients without bronchiectasis or with cylindrical bronchiec-tasis had a lower incidence of pneumonia episodes than those with saccular bronchiectasis. ${ }^{1}$ There is also risk of predisposition to pneumothorax and pneumomediastinum, though it is rare. Conventional pulmonary angiography, has been described as the diagnostic standard. ${ }^{21}$ Because of its less invasive nature, dynamic bolus spiral CT angiography or MDCT angiography can be good alternative diagnostic tools, as compared with conventional angiography. Our patient amply demonstrates this.

Pulmonary function tests in SJMS generally reveal an obstructive pulmonary disorder. Chevrolet and Jumod reviewed 75 cases in the literature and demonstrated the obstructive nature of pulmonary function test, the individual variation in severity and the stable nature of the disease on a long-term basis. Ventilation perfusion(V/Q) scanning of the lungs in this syndrome characteristically shows a matched V/Q defect and a marked trapping on the washout phase on ${ }^{133} \mathrm{Xe}$ scintigraphy. Arslan et al ${ }^{25}$ reported the superiority of this modality of investigation in demonstrating the extent of disease and air trapping as compared to the plain radiographs and HRCT.

The aim of management of SJMS is to prevent and treat intercurrent respiratory infection. Surgical intervention namely lobectomy, pneumonectomy is seldom required except when there is uncontrolled infection of the diseased lung segment or massive hemoptysis. ${ }^{7,6,26}$ The prognosis of SJMS is generally favourable. Bronchiectasis is a possible complication that affects the outcome of SJMS. ${ }^{16}$ Therefore, patients with SJMS must be regularly followed up to look out for this complication and all respiratory tract infection must be adequately treated to prevent its occurrence.

\section{References}

1. Swyer PR, James GCW. A case of unilateral pulmonary Emphysema. Thorax 1953;8:133-136.

2. Macleod WM. Abnormal transradiancy of one lung. Thorax 1954; 9:147-153.

3. Hardy KA, Schidlow DV, Zaeri N. Obliterative bronchiolitis in children. Chest 1988;93:640-666.

4. McLoud TC, Epler GR, Colby TV, Gaensler EA, Carrington CB. Bronchiolitis obliterans. Radiology 1986; 159: 1-8.

5. Isles AF, Masel J, O'Juffy J. Obliterative bronchiolitis due 
to Mycoplasma pneumoniae infection in a child. Pedia Radiol 1987; 17: 109-111.

6. Stokes D, Sigler A, Khouri NF, Talamo RC. Hyperlucent lung (Swyer-James syndrome) after severe Mycoplasma pneumonia infection. Am Rev Respir Dis 1978;117:145-152.

7. Fragonese L, Girosi D, Battistini E. Clinical, physiologic and roentgenographic changes after pneumonectomy in a boy with Macloed/Swyer-James Syndrome and bronchiectasis. Pediatric Pulmonology 2002;34:412-6.

8. McNamara JJ, Urschel HC, Arndt JH, Ulevitch $\mathrm{H}$, Kingsley WB. Idiopathic unilateral hyperlucent lung, The Swyer-James Syndrome. Ann Thorac Surg 1969;7:351-356.

9. Daniel TL, Woodring JH, Vandiviere HM, Wilson MD. Swyer-James syndrome: unilateral hyperlucent lung syndrome. Clin Pediatr 1984;23:393-397.

10. Morita K, Shimizu I, Kamesui T, Watanahe Y, Nonomura A, Kita K. A case of surgical treatment of Swyer-James syndrome. Fpn $\mathcal{F}$ Thorac Cardiovasc Surg 1994;42: 19491952.

11. Yiu MWC, Tsang KWT, Wong Y, Ooi GC. Focal area of hyperlucency on a chest radiograph. Respiration 2001;68: 545-7.

12. Mathur S, Gupta SK, Sarda M, Jaipal U. Swyer-JamesMacleod syndrome with emphysematous bulla. F Indian Med Assoc 1995;93:150-154.

13. Weg JG, Krumholz RA, Hackleroad LE. Unilateral hyperlucent lung: physiologic syndrome. Ann Intern Med $1965 ; 62 ; 675$.

14. Cumming GR, Macpherson RI, Chernick V. Unilateral lung syndrome in children.F Pediatr 1971;78:250-60.

15. Peters ME, Dickie HA, Crummy AB, Kooistra B. SwyerJames-Macleod syndrome: a case with baseline normal chest radiograph. Pediatr Radiol 1982;12:211-3.

16. Lucaya J, Gartner S, Garcia-Pena P. Spectrum of manifestations of Swyer-James-Macleod syndrome. $\mathcal{F}$ Comput Assist Tomogr 1998;22:592-7.
17. Abdullah A. Abba, Abdullah F. Al-Mobeireek. Clinical spectrum of Swyer-James-Macleod syndrome in adults. Saudi Med F 2003;24(2):195-198.

18. Ghossain MA, Achkar A, Buy JN, Rochemaure J, Vadrot D. Swyer-James syndrome documented by spiral CT angiography and high resolution inspiratory and expiratory CT: an accurate single modality exploration. $\mathcal{F}$ Comput Assist Tomogr 1997;21(4):616-8.

19. Peters ME, Dickie HA, Crummy AB, Kooistra B. SwyerJames-Macleod syndrome: a case with baseline normal chest radiograph. Pediatr Radiol 1982;12:211-3.

20. O'Dell CW, Taylor A, Higgins CB, et al. Ventilationperfusion lung images in the Swyer-James syndrome. Nucl Med 1976;121:423-6.

21. Fraser RG, Paré PD, Fraser RS, Genereux GP. Diagnosis of Disease of the Chest. 3rd ed. Philadelphia: Saunders, 1996:2177-86.

22. Moore ADA, Godwin JD, Dietrich PA, Verschakelen JA, Henderson WR. Swyer-James syndrome: CT findings in eight patients. Am F Radiology 1992;158:1211-1215.

23. Thurlbeck WM, Chronic airflow obstruction. In: Thurleck WM(ed), Pathology of the Lung. New York (NY): Thieme Medical; 1988. p. 519-575.

24. Chevrolet JC, Jumod AF. Characteristics of respiratory functional involvement in Macleod's syndrome (SwyerJames syndrome). Scheweiz Med Wochenschr 1987; 117: 1902-1909.

25. Arslan N, Ilgam S, Ozkan M, Yuksekol I, Bulakbasin N, Pabuscu Y. Utility of ventilation and perfusion scan in the diagnosis of young military recruits with an incidental finding of hyperlucent lung. Nucl Med Commun 2001;22: 525-530.

26. Ohri SK, Rutty G, Fountain SW. Acquired segmental emphysema: The enlarging spectrum of Swyer-JamesMacleod Syndrome. Ann Thorac Surg 1993; 56: 120-124. 